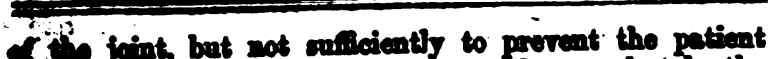
wing a wooden log. He was soon able to undertitse the intine of harnakeeper.

C19n vir. Bnnnah Jones, aged 11, was attacked with violent fobrile symptoms about the beginning of December 1849. In three days, the right leg became very much infamed and awollen. This ended in a formation of matter, which was lanced at the end of three wreeks, and a large quantity of matter escaped. It continued to discharge froely for a long time, and upon examining it with a probe, the tibis was found diseased. About four months afterwards, she fell and fractured the tibia, about an inch belor its tuberosity. No union took place, and the end of the lower portion became gradually exposed, prominent, and discoloured. It was a compound fracture. The patient's concitution was, about two months after the accident, much reakened; and upon a consultation, amputation was thought the most advisable course, which was determinately refused, and the patient was placed under the care of a quacking woman. The bone gradually became more exposed, and I was called in to remove the sequestrum, which was about six inches long; including the whole circumference of the bone at its upper end, but tapered gradually to a point at the lower one. The wound gradually healed, and the leg gradually acquired strength. The tibia was conspicuously deficient, and there was an isthmus of bone, the reverse of the sequestrum in shape, connecting the upper and lower portions. She is able to walk a distance of four or five miles, and uses neither crutch or stick.

In reviewing these cases, it will appear that in Cases IV and $v$ the loss of a large quantity of bone was no obstacle to a firm union. At the same time I would call attention to the facts of there having been in both cases a close approximation of the ends of the bone, and (I would call it) a valuable extent of surface presented at both ends of the wan bone. In Case vi, the bones were kept asunder, until the ends of the bone had become unfit for union, by the integrity of the fibula, the head of which became displaced by the efforts of the muscles, and became to some extent a permanent inconvenience. And to the sound condition of the fibula I attribute the unsuccessful result of the case. And should I again meet with a similar case, I should be disposed to divide that bone at once at the most convenient point. No attempt at union followed the approximation of the bones in this case.

Case vII is scarcely eligible to be classed with the others, as it called for no active interference of the surgeon; and probably the continuity of the tibia was never actually interrupted altogether. But it is, I think, a very singular case, its features are interesting and highly instructive. It is interesting to reflect how far the accident of fracturing the bone prevented nature reproducing a more perfectly modelled portion of bone in place of the sequestrum. I have no doubt of its having hastened the exfoliation, and prevented nature furnishing a more perfect substitute for the lost portion of bone by the injury necessarily inflicted on the shell or matrix.

Any hope of the reproduction of any quantity of lost bone from injury, founded on circumstances which attend the process of necrosis is likely, I fear, to end in disappointment; as it will appear if we take the case of W. P., Case $V I$, as a fair specimen of cases in which a considerable chasm exists between the ends of bones, that the growth of bone does not proceed to any great extent. But the ends grow tapering, granulate, and unite to soft parts, or heal orer as occurs in the stump of an amputated limb. The same condition of the ends of the bones has been remarked upon in most cases of ununited fractures. And such having been found to be the case, and a parallel between the results n cases of amputation and ununited fractures having been traced, may we not infer, with much probability, that isolation from bone is the simple cause in both instances. The isolation in ununited fracture being caused by the interpocition of a fragment of bose, or some of the coft parts. It crems to me very difficult to reconcile the idea of a physical cares of non-union, except in istems trinted with poison,

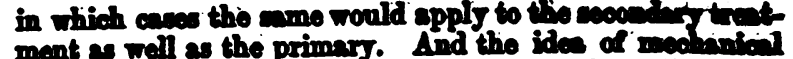
mont as well as the primary. And the ido of noomanich interposition is countenanced by the fect that an ing ments and instrumentalities which hare been found mons Supposing such to be the case, in most instances the besis of treatment becomes evident; vis., to remore the cartilaginous growth from the ends of the bones sufficiently far to obtain an adequate extent of surface of genuine bone at both ends, and to secure their contact without the interposition of anything. And I cannot imagine any mode of proceeding better calculated to obtain those ends than that which is expressed by Dr. Mott, "resection of the fragments and their union by means of wire". When approximating the bones in the case of $\mathrm{R}$. Jones, a large belly of muscle intruded itself, and it was necessary to carry the finger through between the bones to displace it. This is a liability which should also be borne in mind at the onset of the treatment of cases of severe fractures.

The theory of the process by which fractured bones unite and are repaired, appears to be undergoing revision, and is approaching, I think, much nearer to the real state of the case. The old theory of the mechanical ferrule-like agent of callus has for some time struck me as being erroneous. The opinions of Mr. Paget of London, and Dr. J. Hamilton of Buffalo, U.S., have dealt a most serere blow against the old theory. Dr. J. Hamilton (Buffalo Medical Journal, quoted in Association Mrdical Jodrnay, June 10th, 1853) says, "broken bones unite when submitted to the most farourable circumstances by definitive callus, or by a process allied to adhesion, by first intention; but under less farourable circumstances by provisional callus, or by a process allied to granulation, by second intention." I would suggest a slight alteration in the phraseology of this paragraph, by erasing the allusions to callus, and the parallels to union of other structures, and allow bones to unite by the same processes as other structures of the body, viz., by first intention or by granulation. It will be remembered that in the case of J. W., Case III, an elastic band of granulations which could be put on the stretch, was distinctly observed connecting the bones; before any other means of connexion could bo observed. And granulating bone will unite to any other granulating structure that it may chance to come in contact with-be it bone, ligament, muscular fibre, or integument; which, I imagine, would not be the case if the respective structures were governed by different physical laws.

Yerthyr Tydfil, June 1854.

\section{LEAVES FROM THE NOTE-BOOK OF A WEST INDIAN PRACTITIONER.}

\section{By LEWIS ASHENHEIM, M.D.}

I. DISRUPTED PLACENTA : gYRINGIXA THE DTERUS.

JANE TRUEWIe, a coloured, young, unmarried woman, aged about 24, was delivered of her second child on November 8th, 1853; I was informed that she had been in labour about four hours before the infant was born, and that, at the moment of birth, she was told by the midwife in attendance to raise herself up, and stand erect, by laying hold of har (the midwife's) shoulders. The girl did as she was ordered, when the umbilical cord snapped, and she felt a sensation as if "something went back into her". The midwife then introduced her hand into the vagina, and, after a little time, pulled something away, and then said that " all was right." Since her delivery, large quantities of blood were from time to time discharged, sometimes in the form of pure coagula, and sometimes in fluid blood to such a largo extent as to induce her friends to fear that she would inovitably succumb. The discharge, after a day or two, amelt very offensively, and fever was almost constantly precent.

I was sent for on the 2lat of Norember, some thirteen days after delivery. On entering the room where my par tient lay, a dintinet putrefictive odour was very ovidont. 
Fer fentures were pallid, and betrajed great anxiety. Her pules was ansl and rapid, and her other general symptoms puise was anal and rapid, and hercter. There was no tympanitis. On examination per vaginam, I found the internal parts very hot, and lubricated with thin sanious dischare of slight red colour. The os uteri was rather firmly closed, and it was with some difficulty that a finger, well oiled, could be introduced. I could not detect any portion of retained placenta ; and being unwilling, from the distressing and debilitated state in which my patient was, further to dilate the uterine orifice, I decided on syringing the carity of the womb, with the view of first partially, and afterwards effectually, dislodging the placental fragments which I judged were there kept back. Jamaica practitioners, particularly those who practise in the agricultural districts of the island, have not those mechanical appliances at hand of which their more favoured brethren in the mother country can at will avail themselves. Necessity, in consequence, is very frequently the mother of their inventions. I had no apparatus at hand fitted for my purpose; but $I$ succeeded very well in my object by attaching an India-rubber nipple bottle to a No. 6 male silver catheter. The instrument was cautiously passed by means of the left hand, which was introduced into the vagina through the os uteri; and the bottle, which had been previously filled with uteri ; and the bolution of chloride of lime, being closely compressed by the fingers of the right hand, the fluid easily found its way into the uterine cavity. The operation was frequently repeated, and the offensive odour wos sensibly diminished after each application. Small shreds, in a state of putrefaction, were, from time to time discharged; and, with due attention to the constitutional symptoms, the patient was, in the course of ten or twelve days, declared convalescent.

\section{CHLOROFORM IN ASTHMA.}

Case. On Saturday, the 17th of December, 1853, I was called to visit Mr. M. D. C., of this town, whom I found at his store, labouring under a very severe attack of asthma. This gentleman is of a stout plethoric habit, is aged about 58, lives well, and is subject to attacks of an apoplectic nature, for which he has repeatedly been under my care. I prescribed camphor, ipecacuanha, and hyoscyamus, for him. In about half an hour after I left him, I received a second call, which was stated to be urgent. I now found my patient at his residence, and his condition was truly distressing. His countenance was anxious, disturbed, swollen, and livid. The veins of his head were turgid. $\mathrm{He}$ articulated with great difficulty, and in syllables. The roice was whispering. Respiration was extremely laboured, and the sense of pectoral oppression much complained of. The characteristic whistling sound peculiar to asthma was distinctly audible at the extreme end of the apartment, which is one of the most spacious in Falmouth. He was propped up by pillows in a Spanish arm-chair, as it was impossible for him to remain in the recumbent position. He had been sick at the stomach since the first visit. As I was apprehensive of the advent of an attack of apoplexy, I at once determined on the internal administration of chloroform. One drachm of this drug was mixed with four ounces of water, and a dessert-spoonful given, after previous vigorous agitation of the mixture. In about two minutes, he drew a deep inspiration, and, in his usual voice, exclaimed, "Ah! I feel easier." I continued the chloroform in the same dose, every quarter of an hour or twenty minutes, for six doses; and no repetition of this or any other medicine was required to complete the cure, which was highly satisfactory.

II. IMPERFORATE ANOS, OR OCCLUBION OF THE RECTUM: BUCCESSFUL CABES OF OPERATIOX.

Case I. On the 19th of September, 1851, I was called by a black man to see his newly born child, as it had not, according to his statement, passed any evacuation since its birth, nor period of about forty hours. On making the visit, I found the child, which was strong and healthy looking, in the following condition. It screamed almost incessantly, drew up its legs towards the abdomen, and clenched and shook its little fists. The expression of its countenances denoted extreme agony. It, every minute or 80 , cagerly snatched st the breast of the mother; but in a fer seconds it dashed the nipple from its mouth, apparently in a par roxysm of suffering. The skin was hot and dry, and the pulse considerably above the recently born infantile standard. The abdomen was tumefied, and presented a well marked degree of tension. The anus was normal, and readily admitted my little finger, when well oiled. On passing a gum elastic bougie (for which I had previously sent) into this orifice, I detected a slight obstruction after the instrument had been introduced to the extent of nearly three inches. On attempting to force the bougie stilli furee inches. drawing it, I found its conical point turned about a quarter of an inch. I had then little doubt on my mind that the rectum ended in a cul-de-sac; and I proposed operation to the parents, which, after some demur, was acceded to. I first made a slight incision into the posterior part of the anus; and then, with very little trouble, I introduced the whole of the forefinger of my left hand, well oiled, into the anus. I thought that I could just detect the cul-de-sac; and, on requesting my assistant to exercise a little pressure and, on requesting mert of the abdomen, I distinctly felt its descent, and the peculiar touch of an intestine. I now passed a very strong, narrow, straight, sharp pointed bistoury along the palmar aspect of my forefinger, so as to protect the bladder; and pushing onwards, guided by the finger, I pierced the intestine. A copious flow of meconium instantly followed, which was kept up by increased external pressure from above. I was now enabled to insert my finger into the opening made by the knife; and I enlarged it by repeated turnings. I succeeded in passing tents of lint on the bulb of a silver probe into the intestine; but I could not retain them there. A few doses of castor oil, and several manual dilatations, completed the cure.

CASE II. Mr. G. F. C., of this town, a highly respectable gentleman of colour, requested me, on the 7th of November; 1851, to visit his newly born daughter, as both the mother 1851 , to visit his nere alarmed at the non-appearance of the usual characteristic alvine evacuations. The infant had been born about eighteen or twenty hours. There was no. external sign of suffering; but, on pressing the abdomen, which was not at all tumefied, the child drew up its feet, and cried. The anus was perfect. I passed into this a No. 5 gum elastic bougie, the point of which received opposition when about an inch and $a$ half from the orifice. I introduced a little finger, and easily reached the intestine. This, though occluded, did not present the rounded touch of that which is generally understood by the term cul-desac. The presenting surface was flattened, and rather dense to the touch, something like membrane. It receded, but with some degree of resistance, upon pressure of the finger. I passed a silver probe, and, after using a tolerable amount of force, penetrated the closing obstacle, which I believe to have been a membranous septum. On withdrawing the probe, it was covered with viscid meconium. I then broke down the barrier with my left forefinger. This was succeeded by a pretty fair disciurge of thick greenish matter, of the consistence of tar. A tent which was introduced was retained. The meconium continued to flow freely. Small doses of castor oil were administered, which established healthy evacuations; and, in the course of a few days, I felt -myself at liberty to discharge myself from the case. The child is, at this date, in the enjoyment of perfect health.

REMARrs. I have seen but six cases of imperforate anus, or rather occlusion of the rectum, in the living, and only one in the dead subject. I was unfortunate in the result of the first three cases upon which I myself operated; and death also occurred in the fourth case, in which I assisted my friend Dr. Alexander Fiddes, of Kingston, one of the most active and intelligent surgeons in Jamaica. I attribute the success, in the cases above recorded, to the early period at which the operations were performed; and I think I should have been enabled to present a more farour- 


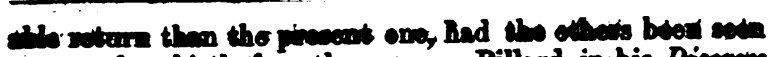

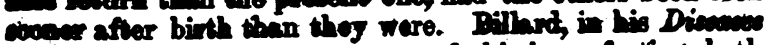
of Infonte, quotes only two cases of this inperfection, both of which terminated fatally. An attentive perusel of these will show that the lapse of time from the birth to the operation exceeded two days. In my own thres fatal cases, I did not any of the infants until the third day after they were born; and in the case with Dr. Fiddes, the child was, I behere, four days old, and to all appearances moxibund at the time when the operation was performed only as a dernier ressort. I am fully impressed with the conviction that there is little or no danger in operating early on simply occluded reetum. The hazard, in my opinion, lies in the delay which exhausts the infant by keeping up irritation. Perhaps, also, the absorption of some virulent agent from the retained meconium may contribute to the induction of death. I have, as before stated, seen but one case in the dead subject which I was permitted to examine. This was in Soptember 1848; and, from my note-book, I briefly sabjoin the heads of the autopsy. The child was three days old when it died.

"The abdomen was puffed, and considerably adranced in putrefaction. The heart was healthy; the lungs were alightly congested; the stomach contained a small quantity of oil ; the intestines contained fluid matter more or less, and lower down meconinm; the rectum was enormousily distended, and, on cutting into it, a large quantity of meconium issued. I carefully examined the anus, and found it imperforate."

There can hardly, I conceive, be a doubt, considering the absence of extensive malformation and disease in this subject, that, if an incision had been made shortly after birth into the exact spot where the anus is usually situated, a successful termination would have been the result of the operation. Unfortunately, it too generally happens that professional assistance is not sought for until the mischief has been done; and I think that it is highly incumbent on all accoucheurs to ascertain the condition of the infant in this particular respect, at all events within six hours after birth. Such a precaution might, in many instances, ward off fatal results. It is, I believe, hardly necessary to state that the present cases do not come within the sphere of an investigation into the methods of operation advocated by Littre, Amussat, and Erichsen. These can only be considered when there is deficiency of formation to a large extent.

Falmonth, Jamaics, May 5th, 185 .

\section{BHBLIOGRAPHCAT NOTICES.}

1 Practical Treatise on the Diseages of the Lorge, HEART, AND AORTA; including the Principles of Physical Diagnosis. By WaLTER HayLr W ALSHe, M.D., Fellow of the Royal College of Physicians, Physician to University College Hospital, etc. Second edition. pp. 812. London : 1854.

Tre first edition of -Dr. WALSHE's Treatise was very favourably received by the profession; the present has been not merely carefully revised, but almost rewritten, and is greatly enlarged. It is divided into two parts, the first containing the Physical Examination of the Lungs, Heart, and Great Vessels, very completely treated of in ten chapters. The second part comprises, in three chapters-I. The Diseases of the Lungs and Appendages; 2. The Diseases of the Heart; 3 . The Diseases of the Great Vescels. $\Delta$ theoretical and practical outline of these diseases is drawn by the author almost entirely from clinical experience; and, in the present edition, several subjects omitted from the former one here been introduced, the articles on prognosis and diagnosis have been extended, and the anatomical character of each morbid state has been added. The work does not contain cases in detail, the introduction of which the author found impracticable without an inconremiont increase of bulk; but extenaive reforences are given

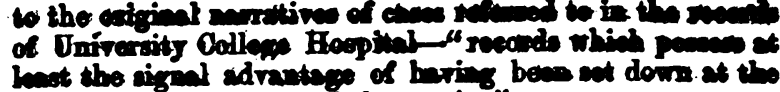
bedaide at the moment of obcervation:".

Aftor an introduction, in which the Clinieal Topegreany of the Chest is very accurntoly marked ont, the anther proceeds to describe the Physical Methods of Diagneain. These vary with the textural properties, tunetional attributes, and peculiarities of eite, of the organs oramined. They consist of -1 . Inspection; 2. Application of the Hand ; 3. Mensuration; 4. Percusoion; 5. Auscultation; 6. Succussion; to which are added, in the chapter on the physical examination of the lungs, 7. The Determination of the Situation of the sarrounding Organs; 8 . The Physical Character of the Air respired. To each of these subjects, in their application to the diseases of the lungs, heart, and great ressels, respectively, a section is devoted; and this pert of the work forms one of the neatest, most eomplete, and probably most aceurate and practical treatises extant on the application of the physical sciences to the patholog of the human chest. It is not so diffuse as some of the continental works on the same subject; nor has the author made that abortive effort at refinement which characterises some of these productions, and which, we think, proves eminently detrimental to the general promulgation of accurate information on this branch of medical scienee, and to the general acquirement of practical tact: but it is a strictly scientific exposition, and a strictly logical one; and what is of most importance of all, it is the clinical appliestion of the principles of physical seience to the art of de tecting disease, by a sound physician and a competent and accurate observer.

That portion of the volume, in which the diseases of the chest and the contained viscera are treated of, bears the impress of the sagacious physician and sound clinical teacher. When we state that it embraces all the well marked and clearly ascertained diseases of the thoracic parietes, the bronchial tubes, the bronchial glands, the pleura, the parenchyma, the mediastina, the heart, the pericardium, the aorta, and the other large vessels, structural and functional; and that the signs and symptoms, the diagnosis, the prognosis, the anatomical characters, the terminations, and the eppropriate treatment, are described-a laboured or argumentative treatise on each will not be expected. It is rather a text-book, in which all that is really known on these several subjects is tersely and accurately stated; disputed points of importance are briefly but fairly put; while the author's own mind has been exerted independently, and he has drawn his delineations of disease from nature as his prototype, and has formed his conclusions of the effects of treatment from his own clinical observation.

An elaborate review of a work of this mature would be impracticable in our pages: and it would not be just to make objections to points abont which we might difier from the anthor, without entering into a critical analysis, and adrancing our grounds of dispute. The objections we might urge would be probably more theoretical than practical, and would bear rather upon the doctrines of our sehooks, and the methods still pursued in teaching practical medicine, than upon any of the author's views. We might, for instance, take exception to the linking of hypertrophy of the heart with hooping-cough nnder this special title-page, or to any treatise embracing pulmonary consumption in which tubercalar disease of the mesentery is barely mentioned, or in which the general symptoms of phthisis are so curtly dismissed, and wherein we meet with no description of the predisposition. The object of the author, however, as stated in his proface to the first edition, bas been to furnish within a moderate compass a guide to the detection and treatment of these diseases; and he has aroided inquiries into their general pathologs

That our readers may form for themselves an opinion of the author's style and mode of handling his subject, we take, almost at hazard, the following paragraphs on the signs and asmptoms of dilated bronchi:-

"565. The addition of dilatation of the tribes to chronie in 